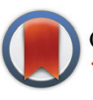

CrossMark $\leftarrow$ click for updates

Cite this: Polym. Chem., 2016, 7, 5322

Received 24th June 2016 Accepted 19th July 2016

DOI: 10.1039/c6py01105e www.rsc.org/polymers

\title{
Dendrons as active clicking tool for generating non-leaching antibacterial materials $\uparrow$
}

\begin{abstract}
Hadi Bakhshi and Seema Agarwal*
We show a novel concept of using dendrons as a tool for making non-active materials antibacterial in a simple way. A dendron is a part of a dendrimer with the advantage of having many peripheral functional groups and a focal point. We used this structural advantage in making an antibacterial polymeric tool for clicking to other non-active polymers and surfaces. We show the success of the concept by making new antibacterial poly(urethane-biuret) dendrons containing quaternary ammonium salts (QASs) on the periphery and a primary hydroxyl group as the focal point in one pot. The chemical structure and thermal properties of the dendrons were fully studied. All quaternized dendrons were stable until above $200{ }^{\circ} \mathrm{C}$. The newly synthesized dendrons show high activity against Escherichia coli (E. coli) and Bacillus subtilis (B. subtilis) as tested by the determination of MIC, MBC values and the Kirby-Bauer assay. The hydroxyl group enabled the attachment of the dendrons to a cotton mat and PU foam, as a reactive additive, bringing them non-leaching fast bactericidal activity. The interaction of urethane and biuret bonds in the dendrons' backbone led to a transparent non-leaching bactericidal coating on the treated glass slides.
\end{abstract}

\section{Introduction}

Dendrimers are interesting macromolecules due to their uniform branched structure that affords a three-dimensional spherical shape with numerous end groups, which is not possible in linear polymers. Their topologically defined structure provides high functionality combined with low viscosity. ${ }^{1,2}$ Due to these reasons, dendrimers have attracted much interest in fields such as biomedicines, ${ }^{3,4}$ catalysts, ${ }^{5}$ coatings ${ }^{6}$ and adhesives. $^{7}$ Meanwhile, the modification of dendrimers to introduce new functionality on the periphery has been considered for many other applications. ${ }^{1,2,8}$ For example, the preparation of dendrimers containing quaternary ammonium salts (QASs) for antibacterial activity was carried out. ${ }^{9-11}$ Since dendrimers exhibit an exponential increase in number of end groups with number of generations, QAS-functionalized dendrimers are expected to have high antibacterial activities in comparison to mono or bivalent biocides. ${ }^{9}$

For many of the applications it is desirable to have a nonleaching (contact-type) antibacterial effect in which there is no contamination from the surroundings or decrease in antibacterial activity with time/use. The antibacterial QASs, in general, are polar molecules soluble in water that leads to leaching

Macromolecular Chemistry II and Bayreuth Center for Colloids and Interfaces, University of Bayreuth, Universitätsstraße 30, 95440 Bayreuth, Germany.

E-mail: agarwal@uni-bayreuth.de; Fax: +49-921-553393; Tel: +49-921-553397

$\dagger$ Electronic supplementary information (ESI) available: Experimental details and extra results. See DOI: 10.1039/c6py01105e when used in the form of physical blends with other nonactive polymers. In the last few years, research attention has been given to the formation of non-leaching-type antibacterial polymers. ${ }^{12-14}$ Different synthetic methods were developed to provide bactericidal QASs as inherent parts of the polymer by using QAS-containing monomers, post-polymerization quaternization or attaching them covalently by polymer analogous reactions, etc. ${ }^{15-19}$ Each time, new synthetic procedures were developed to provide non-leaching antibacterial activity for the polymers, which were accompanied with expensive and time consuming optimization.

In the present work we show antibacterial dendrons as a clicking tool for introducing non-leaching antibacterial activity to other existing non-active polymers. Our concept is to make antibacterial dendrons with peripheral antibacterial units and a functional focal point that can be used for clicking to other wide variety of non-active polymers. Antibacterial poly (urethane-biuret) dendrons containing a primary hydroxyl group as the focal point and QASs on the periphery are made in this work. QASs provide contact-killing bactericidal activity, while the hydroxyl group enabled the dendrons to attach chemically to substrates. The concept was supported by showing a few examples, such as clicking of active dendrons to a cotton mat, using as a reactive additive in polyurethane (PU) foam and coating on a glass surface for generating non-leaching fast-acting antibacterial materials. In the future, this can be extended to make a complete toolbox of similar dendrons with different functional focal points for clicking to appropriate polymers/surfaces. 


\section{Experimental}

All experimental details for the synthesis of dendrons and their analysis are collected in the ESI. $\dagger$

\section{Results and discussion}

\subsection{Synthesis and characterization of dendrons}

Poly(urethane-biuret) dendrons with QASs on the periphery were made using HDI-uretdione, 3DMAPrOH and 6-aminohexanol as starting materials. The carbonyl bonds within isocyanate and uretdione moieties are electrophilic sites for reaction with nucleophiles. ${ }^{20}$ The isocyanate group does not show any specificity during reaction with nucleophilic reagents such as alcohols and amines, while the uretdione ring shows selectivity for reaction with primary amines. ${ }^{20}$ Based on this phenomenon, the preparation of poly(urethane-biuret) dendrons included two steps per generation (Fig. 1): (1) the reaction of free isocyanate groups of HDI-uretdione with an alcohol (3DMAPrOH) resulting in urethane bonds; and (2) the ring-opening reaction of the uretdione moiety with the amine head of 6-aminohexanol leading to the formation of a biuret group. The hydroxyl head of 6-aminohexanol opened the possibility for further reaction with HDI-uretdione. Therefore, this first generation dendron can undergo same reaction sequence as an alcohol, resulting in the second and higher generations (Fig. 1).

We studied the effect of the reaction parameters, i.e., catalyst, temperature and time, for the preparation of dendrons in THF. Although the tertiary amine moiety within 3DMAPrOH can catalyze the reaction of isocyanates and hydroxyl groups, ${ }^{21,22}$ we used an extra catalyst, DBTDL, that is well known to facilitate this reaction. ${ }^{22}$ The rate of free isocyanate consumption was monitored by FTIR spectroscopy (Fig. S1 in ESI $\dagger$ and Table 1). The use of DBTDL decreased the reaction time for the reaction of HDI-uretdione and $3 \mathrm{DMAPrOH}$ and an

Table 1 Effect of DBTDL and temperature on the reaction of HDI-uretdione and 3DMAPrOH

\begin{tabular}{llllll}
\hline & \multicolumn{2}{l}{ With DBTDL } & & \multicolumn{2}{l}{ Without DBTDL } \\
\cline { 2 - 3 } $\begin{array}{llllll}\text { Reaction } \\
\text { temperature } /{ }^{\circ} \mathrm{C}\end{array}$ & $\begin{array}{l}\text { Reaction } \\
\text { time } / \mathrm{min}\end{array}$ & $\begin{array}{l}\text { Yield } \\
(\%)\end{array}$ & & $\begin{array}{l}\text { Reaction } \\
\text { time } / \mathrm{min}\end{array}$ & $\begin{array}{l}\text { Yield } \\
(\%)\end{array}$ \\
\hline 67 & $<1 \mathrm{~min}$ & 96 & & $30 \mathrm{~min}$ & 97 \\
55 & $<1 \mathrm{~min}$ & 94 & & $100 \mathrm{~min}$ & 98 \\
40 & $<1 \mathrm{~min}$ & 95 & & - & - \\
25 & $40 \mathrm{~min}$ & 96 & & - & -
\end{tabular}

DBTDL: dibutyltin dilaurate, HDI-uretdione: hexamethylene diisocyanate uretdione, 3DMAPrOH: 3-dimethylamino-1-propanol. [OH]/[NCO]: 2.2/1, DBTDL: $0.3 \mathrm{wt} \%$ of HDI-uretdione.<smiles>O=C1C(=O)N([N+](=O)[O-])C(=O)N1C[N+](=O)[O-]</smiles>
HDI-uretdione

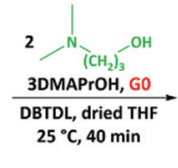

$25^{\circ} \mathrm{C}, \mathbf{4 0} \mathrm{min}$

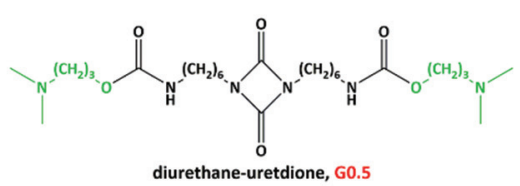

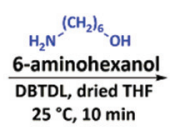
diurethane-uretdione, G0.5

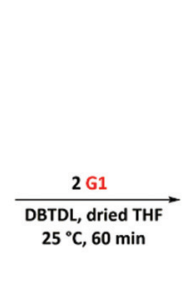

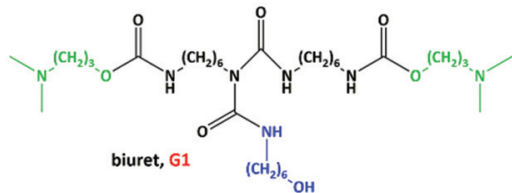

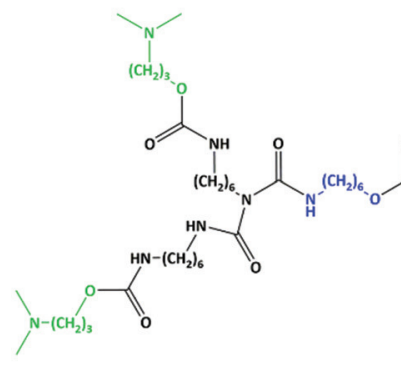<smiles>[1H]C(=O)O[14CH2]N(C)C</smiles>

6-aminohexanol DBTDL, dried THF $25^{\circ} \mathrm{C}, 10 \mathrm{~min}$

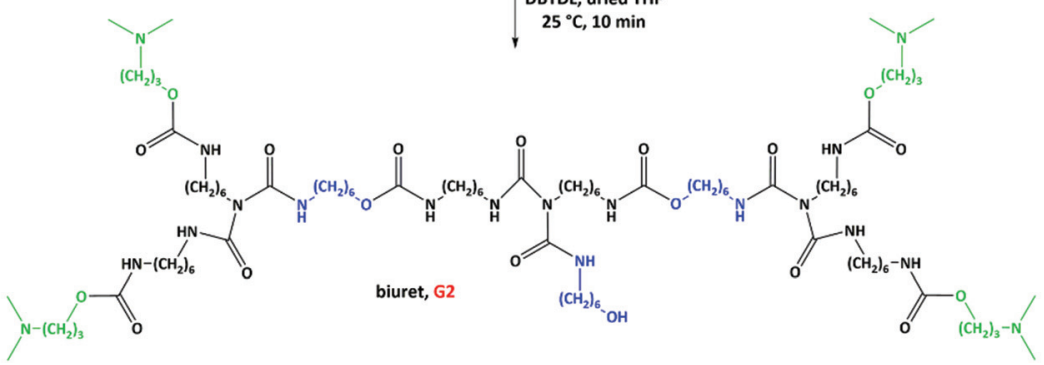

Fig. 1 Reaction pathway for the preparation of the first and second generation of poly(urethane-biuret) dendrons with a hydroxyl focal point. HDI-uretdione: hexamethylene diisocyanate uretdione, 3DMAPrOH: 3-dimethylamino-1-propanol, DBTDL: dibutyltin dilaurate. 
immediate reaction (less than $1 \mathrm{~min}$ ) with high product yield was observed at moderate temperatures $\left(40-67^{\circ} \mathrm{C}\right)$. At room temperature, the same reaction took approximately $40 \mathrm{~min}$ for completion. Due to partial degradation of the uretdione ring, especially at high temperatures as observed in FTIR spectroscopy (the intensity of peak at $1762 \mathrm{~cm}^{-1}$ corresponding to uretdione rings decreased due to partial ring opening), we preferred to continue this step at room temperature in the presence of DBTDL catalyst.

The product obtained from the first step (G0.5) after washing with $n$-hexane and drying at $30^{\circ} \mathrm{C}$ was a white waxy solid. NMR and FTIR spectroscopy confirmed the chemical structure of G0.5 containing tertiary amine groups and an intact uretdione ring. The protons of the methyl $\left(\mathrm{CH}_{3}^{-}\right)$and methylene $\left(-\mathrm{CH}_{2}-\right)$ moieties attached to tertiary amine groups yielded two signals at 2.19 and 2.29 ppm, respectively (Fig. 2a). The methylene protons at the $\alpha$ position of the nitrogen and oxygen atoms of the urethane group appeared as signals at 3.15 and $4.04 \mathrm{ppm}$. The protons of methylene moieties attached to the uretdione ring led to a signal at $3.13 \mathrm{ppm}$. Meanwhile, the carbons of carbonyl moieties in urethane and uretdione groups appeared as signals at 156.7 and $157.8 \mathrm{ppm}$.

In the second step, the uretdione ring of G0.5 reacted selectively with amine head of $6 \mathrm{AHexOH}$ to create a branching point within the dendrons (Fig. 1). This reaction occurred immediately in THF at both 67 and $25{ }^{\circ} \mathrm{C}$ using $20 \mathrm{~mol} \%$ excess of $6 \mathrm{AHexOH}$. FTIR spectra of the reaction mixture showed that the uretdione ring of G0.5 reacted with the amine
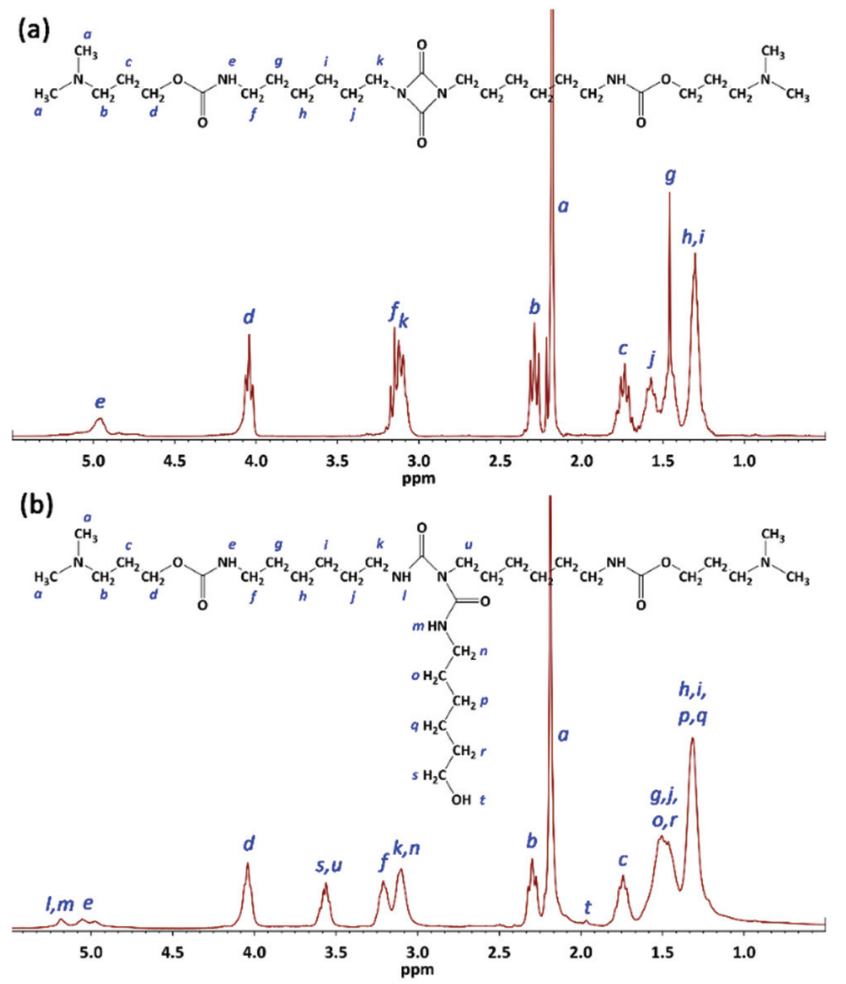

Fig. $2{ }^{1} \mathrm{H}$-NMR spectra for G0.5 (a) and G1 (b) dendrons in $\mathrm{CDCl}_{3}$. group in less than $1 \mathrm{~min}$. After purification through washing with $\mathrm{Et}_{2} \mathrm{O}$ and drying at $50{ }^{\circ} \mathrm{C}, \mathrm{G} 1$ was obtained as a yellow viscous liquid. NMR and FTIR spectroscopy confirmed the chemical structure of the first generation of poly(urethanebiuret) dendrons without the presence of side products and unreacted starting materials. The protons of three methylene moieties at the $\alpha$ positions of biuret groups yielded two signals at 3.10 and $3.64 \mathrm{ppm}$ (Fig. 2b). The methylene protons attached to the hydroxyl group appeared as a signal at $3.64 \mathrm{ppm}$. The proton of the hydroxyl group was also seen at $2.0 \mathrm{ppm}$. The carbons of the carbonyl moieties in biuret groups led to a signal at $151.0 \mathrm{ppm}$.

To minimize the difficult purification procedures, we tried to combine the first and second steps in one reaction pot. For this purpose, HDI-uretdione was first reacted with an equivalent amount of $3 \mathrm{DMAPrOH}$ in the presence DBTDL $(0.3 \mathrm{wt} \%)$ at room temperature for $40 \mathrm{~min}$ and then, equivalent amount of $6 \mathrm{AHeOH}$ was directly added to the reaction mixture, which resulted in the formation of G1. The NMR and FTIR data were same as those obtained previously.

The second generation dendron (G2) was also prepared directly via the reaction of HDI-uretdione with the hydroxyl function of G1 and then the amine head of $6 \mathrm{AHeOH}$ (Fig. 1). The obtained product was a yellow rubbery solid. NMR and FTIR spectroscopy were used for the structural characterization of G2.

To functionalize the dendrons with QASs, the tertiary amine groups were quaternized via alkylation reaction with alkylbromides (Fig. 3). The resulting dendrons are designated as $\mathrm{Gx}-\mathrm{CyBr}$, where $x$ and $y$ denotes the number of generation and alkyl chain length, respectively. The chemical structure of the QAS-functionalized dendrons was studied by NMR spectroscopy. The methyl protons of alkyl moieties appeared at about $0.90 \mathrm{ppm}$. The signal for the protons of methyl groups attached to the nitrogen atoms was shifted from 2.19 to about $3.00 \mathrm{ppm}$, caused by the deshielding effect of quaternized nitrogen atoms. ${ }^{23,24}$ Due to the same reason, the signal of methene protons at the $\alpha$ position of tertiary amines was shifted to a lower field (about $2.95 \mathrm{ppm}$ ). The carbon of the methyl groups near to nitrogen atoms was also shifted from 45.4 to $50.6 \mathrm{ppm}$. Meanwhile, the carbon of the methyl group in alkyl moieties yielded a signal at about $14.0 \mathrm{ppm}$. The qua-

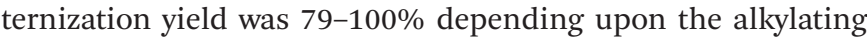
agent.

\subsection{Thermal properties of dendrons}

TGA results showed that all poly(urethane-biuret) dendrons (G1 and G2) were stable at least up to $200{ }^{\circ} \mathrm{C}$, which makes them promising antibacterial additives for thermal processes for mixing with other polymers (Fig. 4a, b and Table 2). All generations underwent a three-step thermal degradation profile (Fig. 4b). The first weight loss occurred at $200-300{ }^{\circ} \mathrm{C}$ attributed to the thermal degradation of urethane and biuret moieties $^{25,26}$ that are recognized as relatively thermally unstable bonds. ${ }^{17,21,27,28}$ The second weight loss $\left(300-420{ }^{\circ} \mathrm{C}\right)$ is due to degradation of the aliphatic backbone of dendrons. 


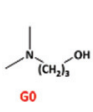

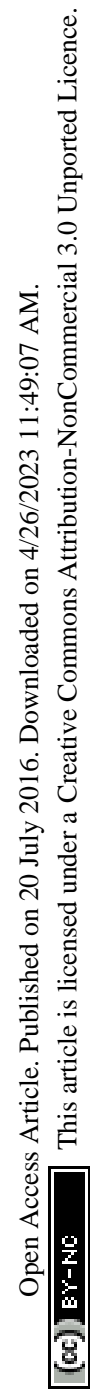

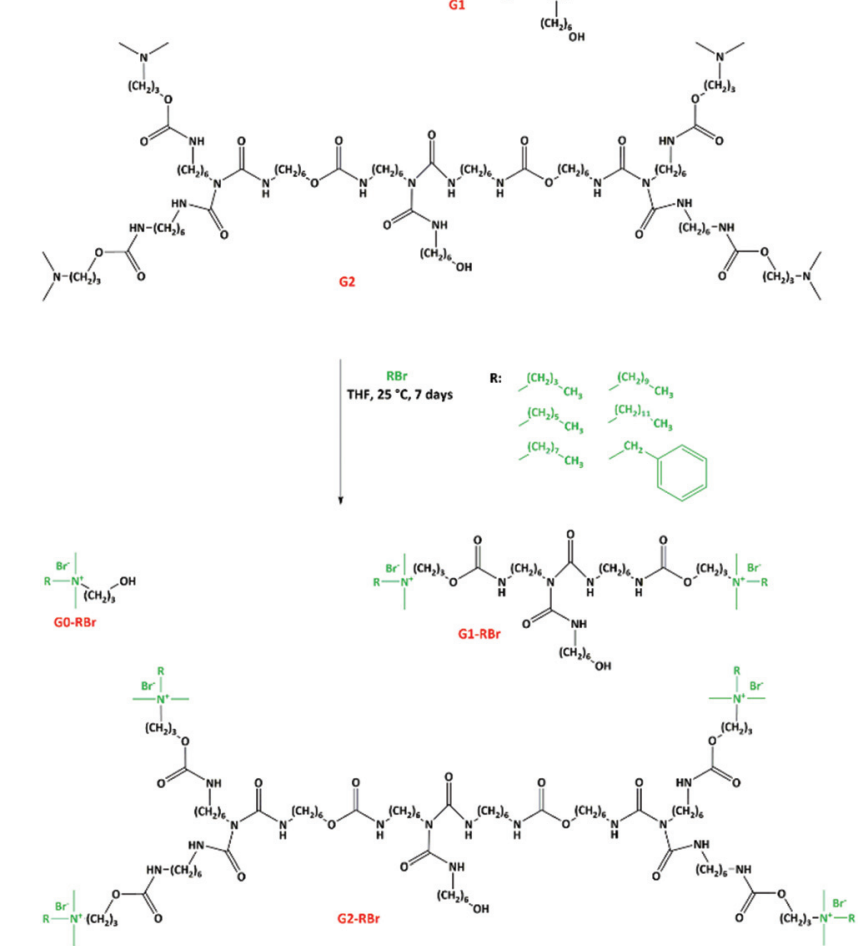

Fig. 3 Reaction pathway for the quaternization of poly(urethane-biuret) dendrons.
Table 2 Thermal properties of the prepared dendrons

\begin{tabular}{lllrr}
\hline Samples & $T_{95 \%} /{ }^{\circ} \mathrm{C}$ & $\begin{array}{l}\text { Char yield at } \\
600{ }^{\circ} \mathrm{C}(\%)\end{array}$ & $T_{\mathrm{g}} /{ }^{\circ} \mathrm{C}$ & $T_{\mathrm{m}} /{ }^{\circ} \mathrm{C}$ \\
\hline G0.5 & 154 & 5.1 & -32 & 81 \\
G1 & 202 & 3.7 & -40 & 52 \\
G2 & 220 & 1.5 & -10 & 116 \\
G0.5-C10Br & 220 & 0.1 & -10 & 82 \\
G0.5-C7Br & 212 & 0.3 & 12 & 96 \\
G1-C4Br & 243 & 0.7 & -28 & 110 \\
G1-C6Br & 243 & 0.3 & -20 & 98 \\
G1-C8Br & 238 & 0.1 & -19 & 89 \\
G1-C10Br & 234 & 0.1 & -22 & 97 \\
G1-C12Br & 231 & 0.1 & -15 & 98 \\
G1-C7Br & 217 & 0.1 & 1 & 111 \\
G2-C10Br & 241 & 0.3 & 7 & 126 \\
G2-C7Br & 218 & 0.1 & 26 & 132
\end{tabular}

TGA and DSC were run at a heating rate of $10{ }^{\circ} \mathrm{C} \min ^{-1}$ under $\mathrm{N}_{2}$ atmosphere.

The third weight loss $\left(420-500{ }^{\circ} \mathrm{C}\right)$ is also related to decomposition of cross-linked aliphatic structures generated during the previous step. ${ }^{17,21,25,26}$

The thermal stability of dendrons was retained even after the quaternization reaction. In fact, all QAS-functionalized dendrons showed higher decomposition onset values (Table 2) in comparison to the corresponding non-functionalized dendrons with a two-step degradation profile and a maximum weight loss around $250-300{ }^{\circ} \mathrm{C}$ (Fig. $4 \mathrm{c}$ and d). The TGA and
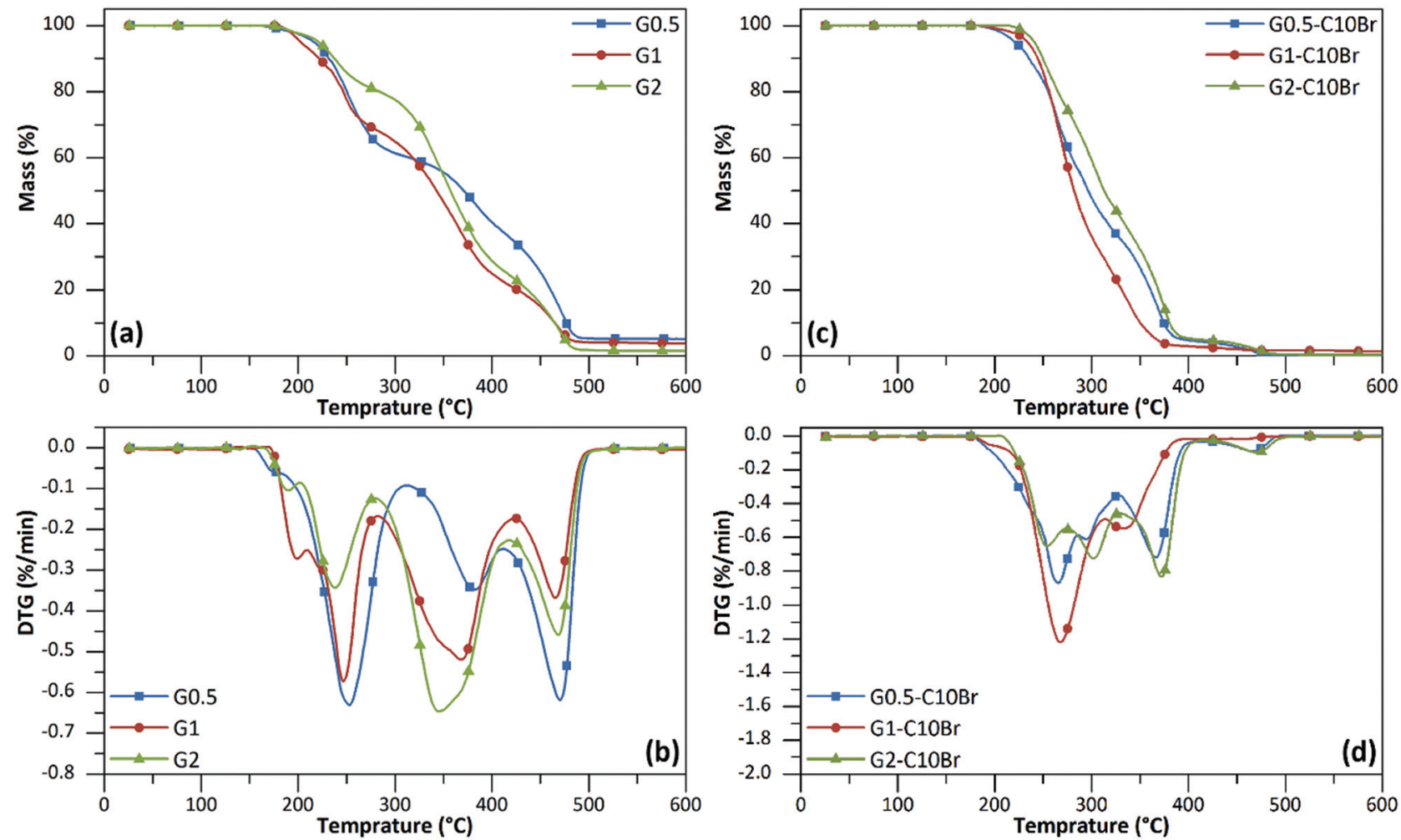

Fig. 4 TGA $(a, c)$ and DTG $(b, d)$ curves of dendrons under $\mathrm{N}_{2}$ atmosphere. The heating rate was $10{ }^{\circ} \mathrm{C} \mathrm{min}^{-1}$. 
DTG curves of other dendrons are depicted in the ESI (Fig. S2 and $3 \dagger$ ).

All dendrons showed a glass transition $\left(T_{\mathrm{g}}\right)$ and a broad endothermic melting peak $\left(T_{\mathrm{m}}\right)$ depending on their chemical structures as evidenced by DSC (Table 2). G1 showed lower $T_{\mathrm{g}}$ and $T_{\mathrm{m}}$ values than the corresponding uretdione precursor (G0.5), which is as a result of its lower symmetry. ${ }^{29}$ As expected, both $T_{\mathrm{g}}$ and $T_{\mathrm{m}}$ values were higher for the second generations. For all dendrons, introducing QAS within their structure shifted their the $T_{\mathrm{g}}$ and $T_{\mathrm{m}}$ values to higher temperatures. This phenomenon is attributed to strong ionic interaction between QAS moieties. ${ }^{17,21,23,24,30}$

\subsection{Antibacterial activity of QAS-functionalized dendrons}

To investigate the bactericidal activity of dendrons, their MIC and MBC values were determined (Fig. 5). MIC is defined as the minimal amount of a substance that is needed to inhibit the visible growth of bacteria after $18 \mathrm{~h}$ of incubation at $37^{\circ} \mathrm{C}$, and $\mathrm{MBC}$ is the minimal amount needed to kill $\geq 99.9 \%$ of the bacteria after $18 \mathrm{~h}$ of incubation at $37^{\circ} \mathrm{C} .{ }^{31-33}$ Both MIC and MBC values were lower for QAS-G1 dendrons with longer alkyl moieties, whereas the highest antibacterial activity was observed for G1-C10Br (Fig. 5a and b). This trend was expected since the length of the alkyl groups of QASs is a strong parameter affecting bactericidal performance. This phenomenon has been frequently studied for low molecular weight, ${ }^{38,39}$ polymeric $^{34,35}$ and dendrimeric structures ${ }^{36,37}$ of QASs. In fact, the hydrophilic-lipophilic balance is highly important for the antibacterial activity of polycations. Furthermore, mono-QASfunctional $\mathrm{G} 0-\mathrm{C} 10 \mathrm{Br}$ prepared from direct reaction of $3 \mathrm{DMPrOH}$ and $\mathrm{C} 10 \mathrm{Br}$ showed significantly higher MIC and MBC values than all QAS-functionalized dendrons based on C10Br (Fig. 5c and d). Similar observations were obtained for QAS-functionalized dendrons based on C7Br (Fig. S4 in ESI $\dagger$ ). This observation proved that the QAS-functionality of dendrons is mainly responsible for their antibacterial activity. ${ }^{9}$ The MIC and MBC values for QAS-G2 dendrons were not measured since they were not soluble in aqueous media and the obtained values cannot be compared with those for lower generation water soluble dendrons.

Although all dendrons were highly active against both $S$. subtilis and E. coli, the bactericidal performance was much higher for $S$. subtilis than $E$. coli, which is in agreement with previously reported results on QAS-containing polymers. ${ }^{38-40}$ The phenomenon is related to the differences in the cell membrane structures of $S$. subtilis and E. coli bacteria. The more hydrophilic nature of the Gram-negative $E$. coli and its multilayered cell structure give higher resistance against antibacterial agents such as QASs. ${ }^{41,42}$

The antibacterial activity was also proved by the agar diffusion (Kirby-Bauer) method. ${ }^{17,21,31,43}$ QAS-G2 dendrons did not show any inhibition zone for both $E$. coli and $S$. subtilis bacteria, however, QAS-G0.5 and QAS-G1 dendrons showed significant inhibition zones (Table S1 in ESI $\dagger$ ). This is due to the
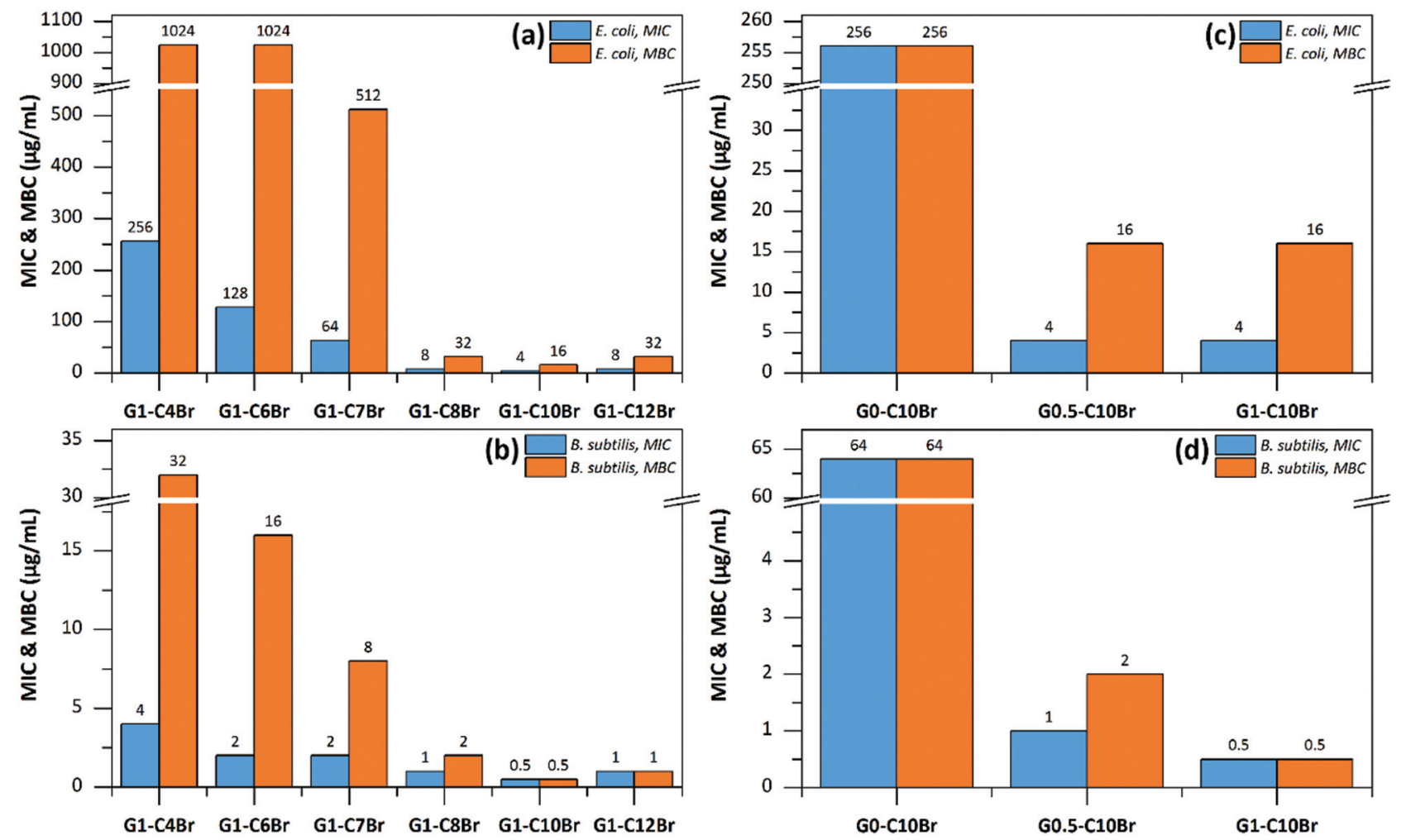

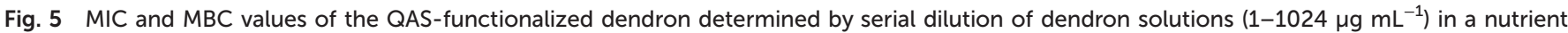
broth containing $10^{6} \mathrm{CFU} \mathrm{mL} \mathrm{m}^{-1}$ of $E$. coli $(\mathrm{a}, \mathrm{c})$ or $B$. subtilis $(\mathrm{b}, \mathrm{d})$. 
partial solubility of QAS-G0.5 and QAS-G1 dendrons in aqueous media due to their lower molecular weight in comparison to QAS-G2 dendrons.

\subsection{Grafting of QAS-functionalized dendrons on a cotton mat}

The hydroxyl group within the focal point of QAS-functionalized dendrons enabled future chemical reactions, such as attachment to substances. To show this potency, G2-C10Br were grafted onto a non-woven cotton mat using glyoxal as the coupling crosslinking agent and $\mathrm{MgCl}_{2}$ as catalyst ${ }^{44,45}$ (Fig. 6a). The weight gain for the cotton mat after grafting was $4.9 \%$. Meanwhile, grafting of the mat with G2-C10-Br changed its color from white to light brown (Fig. S5 in ESI $\dagger$ ). The grafting of G2-C10Br on the cotton mat was studied via ATR-FTIR spectroscopy. The FTIR spectrum of the grafted mat was as same as that of the unmodified cotton mat, except for the

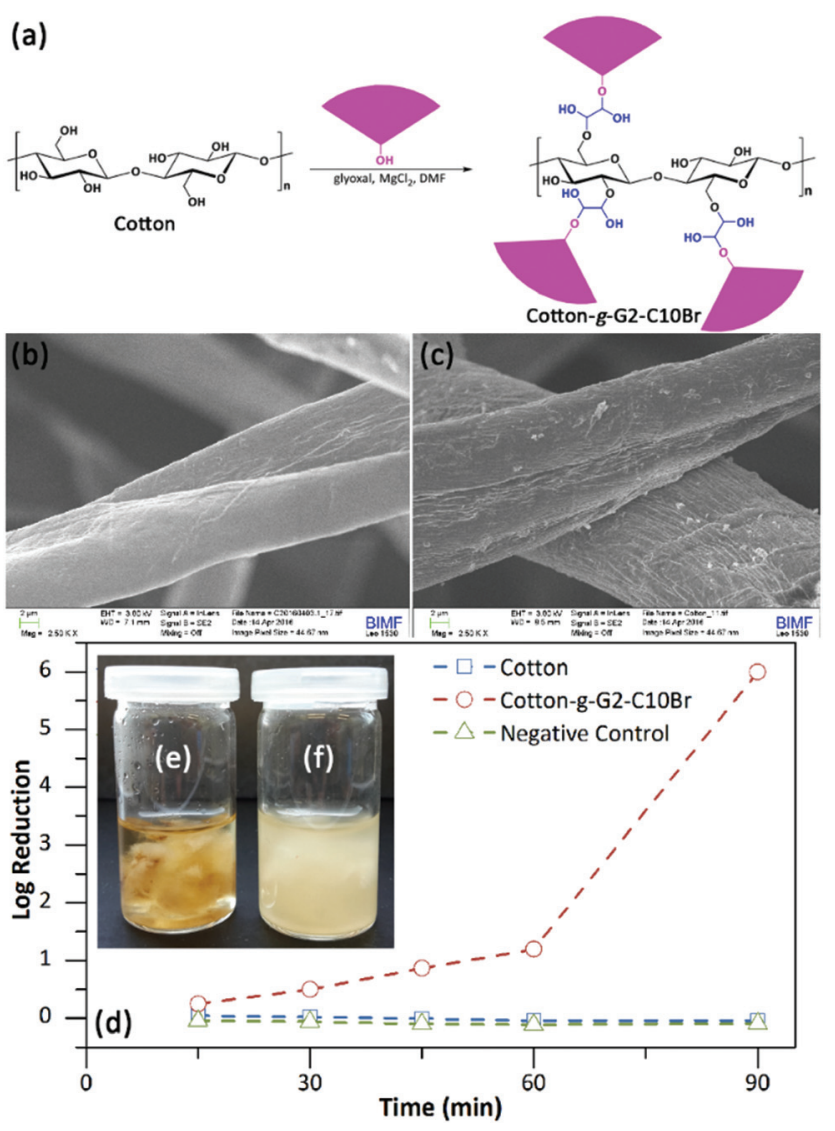

Fig. 6 Reaction pathway for grafting of G2-C10Br onto a cotton mat (a), SEM images of the cotton mat before (b) and after (c) grafting with $\mathrm{G} 2-\mathrm{C} 10 \mathrm{Br}$ at 2500 magnifications. Time-dependent reduction of bacteria for a $4 \mathrm{~mL}$ suspension of $E$. coli with an initial concentration of $10^{6} \mathrm{CFU} \mathrm{mL} \mathrm{mL}^{-1}$ in PBS upon contact with $40 \mathrm{mg}$ of samples at room temperature, given in logarithmic scale (d). A flask containing bacteria and no sample was used as negative control. The ability of cotton mat before (f) and after (e) grafting with $\mathrm{G} 2-\mathrm{C} 10 \mathrm{Br}$ to inhibit the growth of E. coli $(40 \mathrm{mg}$ sample in $4 \mathrm{~mL}$ bacteria suspension with an initial concentration of $10^{6} \mathrm{CFU} \mathrm{mL}{ }^{-1}$ ) in nutrient broth at $37^{\circ} \mathrm{C}$ after 18 hours. Growth of the bacteria led to turbidity of the medium. appearance of new peaks at 1689 and $14523 \mathrm{~cm}^{-1}$ that are related to urethane and biuret bonds $(\mathrm{NC}=\mathrm{ON}, \nu, \mathrm{CO}-\mathrm{NH}, \nu$, $\mathrm{OCON}-\mathrm{H}, \delta$ ) in the structure of grafted dendrons (Fig. S6 in ESI $\dagger$ ). Thus, the dendrons were successfully attached on the cotton mat.

The surface of the cotton mat before and after treatment with G2-C10Br was also investigated via SEM (Fig. 6b and c). The surface of untreated cotton fibers was smooth, but the grafted mat showed a rougher surface with a layered structure. EDX analysis was used to follow up the $\mathrm{Br}$ element within grafted dendrons on the cotton mat, but no $\mathrm{Br}$ was detected. This can be due to the low Br content (less than $0.6 \mathrm{wt} \%$ ) of the grafted mat and the low sensitivity of EDX for the detection of Br element.

The antibacterial activity of the cotton mat grafted with G2C10Br was investigated via the shaking flask method. To this end, samples (40 mg) were contacted with a bacterial suspension ( $4 \mathrm{~mL}, 10^{6} \mathrm{CFU} \mathrm{mL} \mathrm{m}^{-1}$, in PBS) at room temperature and the bacterial content was determined through serial dilution counting. Results showed that Cotton-g-G2-C10Br killed both E. coli and B. subtilis bacteria after 90 min contact, yielding a $\log$ reduction of 6 . Studying the kinetics of bacterial reduction indicated that the content of $E$. coli decreased during contact with the grafted mat and more than $90 \%$ of bacteria were killed after 60 min contact (log of reduction of 1, Fig. 6d). Normally, a log reduction of more than 3 is considered as bactericidal, and a $\log$ reduction of less than 3 is considered to be bacteriostatic. $^{46,47}$ To check this, $100 \mu \mathrm{L}$ of the bacteria suspension contacted with Cotton- $g-\mathrm{G} 2-\mathrm{C} 10 \mathrm{Br}$ for 90 min was transferred to a nutrient agar plate and incubated at $37{ }^{\circ} \mathrm{C}$ overnight. The lack of bacterial growth showed the bactericidal effect of the grafted mat. The bactericidal performance of the grafted mat was also tested at nutritive conditions by contacting it $(40 \mathrm{mg})$ with a bacterial suspension $\left(4 \mathrm{~mL}, 10^{6} \mathrm{CFU} \mathrm{mL}^{-1}\right)$ in nutrient broth at $37^{\circ} \mathrm{C}$. After 18 hours, no bacteria grew in the presence of Cotton- $g-\mathrm{G} 2-\mathrm{C} 10 \mathrm{Br}$ (Fig. 6e), but bacterial growth resulted in the turbidity of the medium for an untreated mat (Fig. 6f). It is worth mentioning that the antibacterial activity of Cotton- $g-\mathrm{G} 2-\mathrm{C} 10 \mathrm{Br}$ in nutrient broth was bacteriostatic. Meanwhile, Cotton-g-G2-C10Br did not show any inhibition zone against either $E$. coli or $S$. subtilis bacteria (Fig. S7 in ESI $\dagger$ ). This proved the chemical anchoring of dendrons on cotton fibers, preventing their possible leaching into the environment.

\subsection{Preparation of PU foam containing QAS-functionalized dendrons}

The QAS-functionalized dendrons can also be used as a reactive additive for the preparation of PU foams. To accomplish this, PU foams based on PEG1000, PTMG1000 and HDI with or without $2 \mathrm{wt} \%$ of G2-C10Br were prepared. ${ }^{48,49}$ The hydroxyl group within the focal point of the dendrons enables them to attach to a foam backbone in the course of polycondensation reactions, providing bactericidal activity. SEM and optical microscopy images (Fig. 7a and S8 in ESI $\dagger$ ) showed that the prepared PU foam had an open-cell structure with a cell dia- 


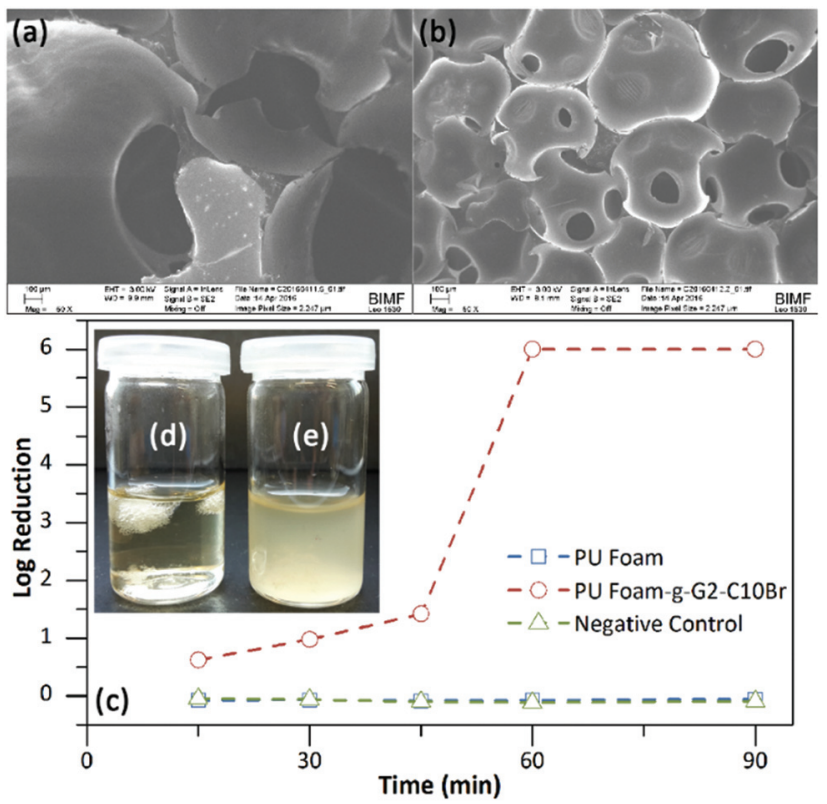

Fig. 7 SEM images of $\mathrm{PU}$ foams without (a) or with (b) $\mathrm{G} 2-\mathrm{C} 10 \mathrm{Br}$ at 50 magnifications. Time-dependent reduction of bacteria for a $4 \mathrm{~mL}$ suspension of $E$. coli with an initial concentration of $10^{6} \mathrm{CFU} \mathrm{mL}^{-1}$ in PBS upon contact with $40 \mathrm{mg}$ of sample at room temperature, given in logarithmic scale (c). A flask containing bacteria and no sample was used as a negative control. The ability of PU foams with (d) or without (e) G2-C10Br to inhibit the growth of E. coli $40 \mathrm{mg}$ sample in $4 \mathrm{~mL}$ bacteria suspension with an initial concentration of $10^{6} \mathrm{CFU} \mathrm{mL}{ }^{-1}$ ) in nutrient broth at $37^{\circ} \mathrm{C}$ after 18 hours. Growth of the bacteria led to turbidity of the medium.

meter of 500-1500 $\mu \mathrm{m}$. Incorporation of $\mathrm{G} 2-\mathrm{C} 10 \mathrm{Br}$ in the foam formulation not only yielded a more homogenous structure but also significantly decreased the cell size to $200-400 \mu \mathrm{m}$ (Fig. 7b and S8 in ESI $\dagger$ ). In fact, G2-C10Br acted as a surfactant to decrease the surface tension and emulsify the water molecules resulting in uniform foaming reactions, promoted nucleation of $\mathrm{CO}_{2}$ bubbles, and stabilization of the cell walls during the polycondensation reaction. ${ }^{50}$

According to shaking flask results, PU foam containing G2C10Br can kill either $E$. coli or B. subtilis bacteria after $90 \mathrm{~min}$ contact ( $\log$ of reduction of 6). Bacterial reduction kinetic study showed that $E$. coli bacteria were killed easily with PU Foam- $g-\mathrm{G} 2-\mathrm{C} 10 \mathrm{Br}$ and more than $90 \%$ of bacteria were destroyed upon 30 min contact ( $\log$ of reduction of 1, Fig. 7c). No bacteria growth was also observed for PU foam containing G2-C10Br in nutrient broth (Fig. 7d), while bacteria grew rapidly in the presence of pure PU foam (Fig. 7e). The antibacterial activity of PU Foam- $g$-G2-C10Br in both PBS and nutrient broth was bactericidal. As expected, no inhibition zone was detected for PU foam containing G2-C10Br against both E. coli and $S$. subtilis bacteria (Fig. S9 in ESI†).

\subsection{Coating of QAS-functionalized dendrons on a glass surface}

The flexibility of dendrimers is a function of their generation number, branching multiplicity and bond freedom. ${ }^{51}$
Low-generation and flexible dendrimers can adsorb on surfaces via multiple interactions and form a film. ${ }^{52,53}$ To demonstrate this potency for the prepared QAS-functionalized dendrons, their solutions in DMF $\left(100 \mu \mathrm{L}, 4 \mathrm{~g} \mathrm{~L}^{-1}\right)$ were cast on glass slides and dried in a vacuum oven at $50{ }^{\circ} \mathrm{C}$. To ensure sufficient interaction of the surface with the polar moieties of dendrons, glass slides were treated previously with piranha solution $\left(\mathrm{H}_{2} \mathrm{SO}_{4} / \mathrm{H}_{2} \mathrm{O}_{2}, 3: 1 \mathrm{v} / \mathrm{v}\right)$ to form hydroxyl groups on their surface. ${ }^{54}$ All of the prepared films were smooth and transparent (Fig. S10 in ESI†). Immersing the coated glass slides in DW resulted in the detachment of films based on QAS-G1 dendrons due to their partial solidity in water, while the QAS-G2 dendrons films remained attached even after 1 day.

The glass surface coated with $\mathrm{G} 2-\mathrm{C} 10 \mathrm{Br}$ displayed an increase in water contact angle $\left(79 \pm 6^{\circ}\right.$, Fig. $\left.8 \mathrm{~b}\right)$ in comparison to an uncovered slide $\left(38 \pm 4^{\circ}\right.$, Fig. $\left.8 \mathrm{a}\right)$. The reason behind this observation can be attributed to the conformation of the dendrons on the glass surface. A crude model for the conformation of G2-C10Br absorbed on a polar surface is depicted in Fig. 8c. In this model, QAS-functionalized dendrons interact
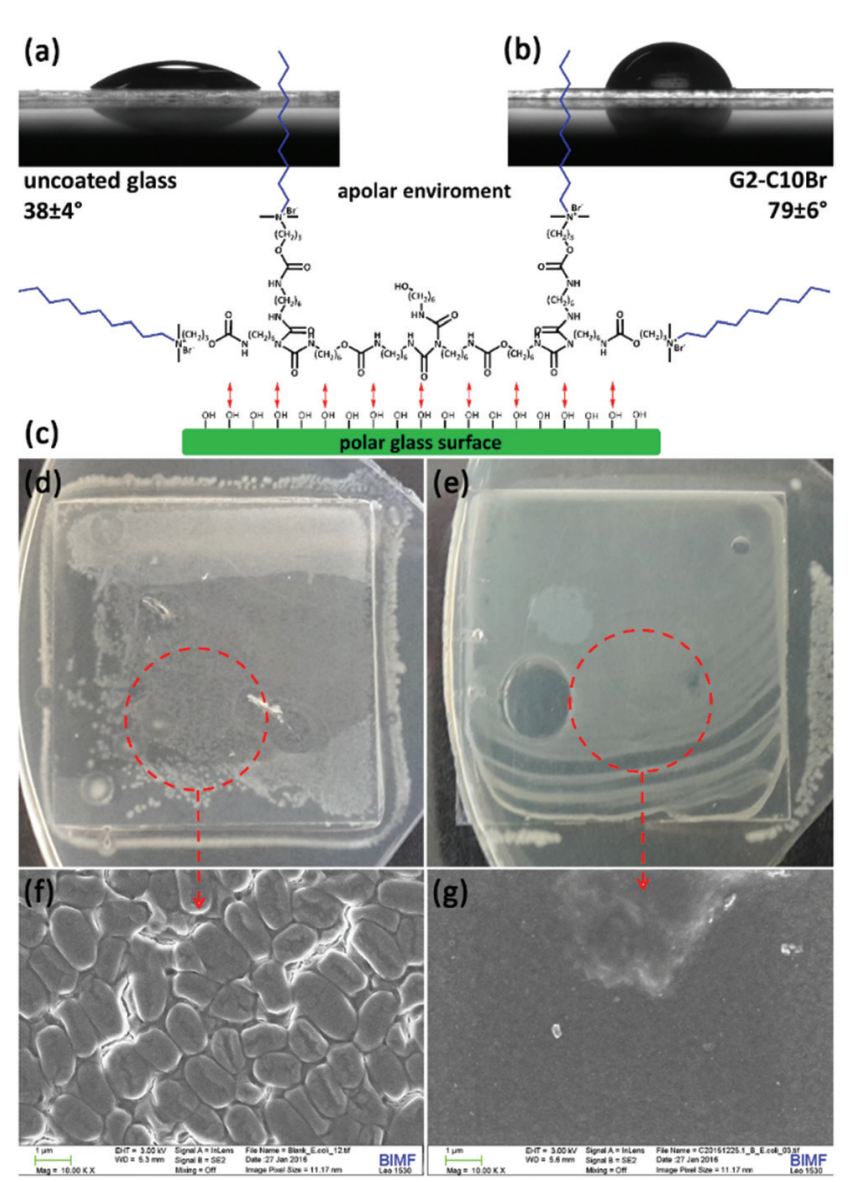

Fig. 8 Contact angle of a water droplet on a glass slide before (a) and after (b) coating with $\mathrm{G} 2-\mathrm{C} 10 \mathrm{Br}$. A crude model for the conformation of $\mathrm{G} 2-\mathrm{C} 10 \mathrm{Br}$ dendrons on a polar surface (c). Pictures and SEM ilmages for uncoated $(\mathrm{d}, \mathrm{f})$ and coated $(\mathrm{e}, \mathrm{g})$ glass slides contacted with $E$. coli $\left(10^{6} \mathrm{CFU}\right)$ after incubation at $37^{\circ} \mathrm{C}$ overnight. SEM images are at 10000 magnifications. 
with the polar surface via their urethane and biuret bonds, while the octyl groups oriented toward the upper apolar atmosphere and formed a hydrophobic layer.

The antibacterial activity of glass surfaces coated with G2$\mathrm{C} 10 \mathrm{Br}$ was studied by seeding bacteria $\left(10^{6} \mathrm{CFU}\right)$ on them, covering with a layer of nutrient agar and incubating at $37{ }^{\circ} \mathrm{C}$ overnight. $^{39}$ The coated glasses were highly effective against $E$. coli and no white dot corresponding to colony growth was observed (Fig. 8e), while bacteria grew and covered the surface of uncoated glass (Fig. 8d). SEM images of these surfaces indicated the formation of a bacterial biofilm on the uncoated glass slide (Fig. 8f), but no bacteria survived and grew on the surface of glasses coated with G2-C10Br (Fig. 8g). Similar observations were also recorded for B. subtilis, which showed the contact-killing bactericidal activity of the glasses coated with QAS-functionalized dendrons.

\section{Conclusion}

QAS-functionalized poly(urethane-biuret) dendrons were prepared using HDI-uretdione, 3DMAPrOH and 6-aminohexanol as starting materials. Speed, simplicity and fewer purification steps are some advantages of this synthetic route. QASs on the periphery provide contact-killing bactericidal activity, while the hydroxyl group enabled the dendrons to attach chemically to substances. Therefore, these antibacterial dendrons can be used as tools for the modification of other non-active materials. Toward this end, G2-C10Br were successfully grafted onto a cotton mat and used as a reactive additive in PU foam formation bringing them non-leaching, fast bactericidal activity. The interaction of urethane and biuret bonds in the dendrons' backbone can also be used to form a layer on polar substrates. Lower generation dendrons with longer alkyl chains displayed the highest antibacterial activity. However, due to its lower aqueous solubility, higher generation $\mathrm{G} 2-\mathrm{C} 10 \mathrm{Br}$ was the better candidate to form a transparent layer on treated glass slides surfaces providing them with bactericidal performance.

\section{Acknowledgements}

Dr Hadi Bakhshi acknowledges the Alexander von Humboldt Foundation for financial support during this research. The authors are also grateful to the Covestro company for providing Desmodur® N 3400.

\section{References}

1 E. Abbasi, S. F. Aval, A. Akbarzadeh, M. Milani, H. T. Nasrabadi, S. W. Joo, Y. Hanifehpour, K. NejatiKoshki and R. Pashaei-Asl, Nanoscale Res. Lett., 2014, 9, 247.

2 Dendrimers: Towards Catalytic, Material and Biomedical Uses, ed. A.-M. Caminade, C.-O. Turrin, R. Laurent, A. Ouali and B. Delavaux-Nicot, John Wiley \& Sons, United Kingdom, 2011.
3 H. Gheybi and M. Adeli, Polym. Chem., 2015, 6, 2580-2615.

4 X. Ma, Z. Zhou, E. Jin, Q. Sun, B. Zhang, J. Tang and Y. Shen, Macromolecules, 2013, 46, 37-42.

5 W.-X. Zhao, N. Liu, G.-W. Li, D.-L. Chen, A.-A. Zhang, M.-C. Wang and L. Liu, Green Chem., 2015, 17, 29242930.

6 A. Sarkar, P. I. Carver, T. Zhang, A. Merrington, K. J. Bruza, J. L. Rousseau, S. E. Keinath and P. R. Dvornic, J. Membr. Sci., 2010, 349, 421-428.

7 M. W. Grinstaff, Biomaterials, 2007, 28, 5205-5214.

8 X. Yang, H. Shang, C. Ding and J. Li, Polym. Chem., 2015, 6, 668-680.

9 E. Fuentes-Paniagua, J. M. Hernández-Ros, M. SánchezMilla, M. A. Camero, M. Maly, J. Pérez-Serrano, J. L. CopaPatiño, J. Sánchez-Nieves, J. Soliveri, R. Gómez and F. J. de la Mata, RSC Adv., 2014, 4, 1256-1265.

10 S. Charles, N. Vasanthan, D. Kwon, G. Sekosan and S. Ghosh, Tetrahedron Lett., 2012, 53, 6670-6675.

11 D. Gangadharan, N. Dhandhala, D. Dixit, R. S. Thakur, K. M. Popat and P. S. Anand, J. Appl. Polym. Sci., 2012, 124, 1384-1391.

12 Y. Xue, H. Xiao and Y. Zhang, Int. J. Mol. Sci., 2015, 16, 3626-3655.

13 R. Nigmatullin and F. Gao, Macromol. Mater. Eng., 2012, 297, 1038-1074.

14 L. Timofeeva and N. Kleshcheva, Appl. Microbiol. Biotechnol., 2011, 89, 475-492.

15 H. Wang, M. Langner and S. Agarwal, Polym. Eng. Sci., 2016, DOI: $10.1002 /$ pen.24347.

16 M. J. Saif, J. Anwar, N. Idrees, N. Athir, T. H. Bokhari and W. uz-Zaman, e-Polym., 2014, 14, 391-396.

17 H. Bakhshi, H. Yeganeh, S. Mehdipour-Ataei, A. Solouk and S. Irani, Macromolecules, 2013, 46, 7777-7788.

18 A. Yari, H. Yeganeh and H. Bakhshi, J. Mater. Sci.: Mater. Med., 2012, 23, 2187-2202.

19 C. Mattheis, H. Wang, M. C. Schwarzer, G. Frenking and S. Agarwal, Polym. Chem., 2013, 4, 707-716.

20 D. A. Wicks and Z. W. Wicks Jr., Prog. Org. Coat., 1999, 36, 148-172.

21 H. Bakhshi, H. Yeganeh, A. Yari and S. Karbalainezhad, J. Mater. Sci., 2014, 49, 5365-5377.

22 D. K. Chattopadhyay and K. V. S. N. Raju, Prog. Polym. Sci., 2007, 32, 352-418.

23 H. Bakhshi, H. Yeganeh, S. Mehdipour-Ataei, M. A. Shokrgozar, A. Yari and S. N. Saeedi-Eslami, Mater. Sci. Eng., C, 2013, 33, 153-164.

24 H. Bakhshi, H. Yeganeh and S. Mehdipour-Ataei, J. Biomed. Mater. Res., Part A, 2013, 101A, 1599-1611.

25 A. Z. Mohd-Rus, T. J. Kemp and A. J. Clark, Prog. React. Kinet. Mech., 2009, 34, 1-41.

26 I. Javni, Z. S. Petrović, A. Guo and R. Fuller, J. Appl. Polym. Sci., 2000, 77, 1723-1734.

27 N. Grassie and G. A. P. Mendoza, Polym. Degrad. Stab., 1985, 10, 267-286.

28 F. Gaboriaud and J. P. Vantelon, J. Polym. Sci., Polym. Chem. Ed., 1982, 20, 2063-2071. 
29 S. Reemers, A. Mourran, H. Keul and M. Müller, J. Polym. Sci., Part A: Polym. Chem., 2006, 44, 1372-1386.

30 N. Kebir, I. Campistron, A. Laguerre, J. F. Pilard, C. Bunel and T. Jouenne, Biomaterials, 2007, 28, 42004208.

31 C. Mattheis, H. Wang, C. Meister and S. Agarwal, Macromol. Biosci., 2013, 13, 242-255.

32 C. Mattheis, M. Zheng and S. Agarwal, Macromol. Biosci., 2012, 12, 341-349.

33 K. Xu, J.-X. Wang, X.-L. Kang and J.-F. Chen, Mater. Lett., 2009, 63, 31-33.

34 E. F. Panarin, M. V. Solovskii, N. A. Zaikina and G. E. Afinogenov, Makromol. Chem., 1985, 9, 25-33.

35 T. Ikeda, S. Tazuke and Y. Suzuki, Makromol. Chem., 1984, 185, 869-876.

36 C. Z. Chen, N. C. Beck-Tan, P. Dhurjati, T. K. van Dyk, R. A. LaRossa and S. L. Cooper, Biomacromolecules, 2000, 1, 473-480.

37 C. Z. Chen, N. C. B. Tanb and S. L. Cooper, Chem. Commun., 1999, 1585-1586.

38 C. Mattheis, Y. Zhang and S. Agarwal, Macromol. Biosci., 2012, 12, 1401-1412.

39 N. Pasquier, H. Keul, E. Heine and M. Moeller, Biomacromolecules, 2007, 8, 2874-2882.

40 E. H. Westman, M. Ek, L. E. Enarsson and L. Wagberg, Biomacromolecules, 2009, 10, 1478-1483.

41 L. A. B. Rawlinson, S. M. Ryan, G. Mantovani, J. A. Syrett, D. M. Haddleton and D. J. Brayden, Biomacromolecules, 2010, 11, 443-453.
42 B. Gottenbos, H. C. Mei, F. Klatter, P. Nieuwenhusi and H. J. Busscher, Biomaterials, 2002, 23, 1417-1423.

43 A. Yari, H. Yeganeh, H. Bakhshi and R. Gharibi, J. Biomed. Mater. Res., Part A, 2014, 102, 84-96.

44 M. M. G. Fouda, A. El Shafei, S. Sharaf and A. Hebeish, Carbohydr. Polym., 2009, 77, 651-655.

45 H.-M. Choi, J. H. Kim and S. Shin, J. Appl. Polym. Sci., 1999, 73, 2691-2699.

46 B. Boonkaew, M. Kempf, R. Kimble, P. Supaphol and L. Cuttle, Burns, 2014, 40, 89-96.

47 D. B. Hoellman, G. A. Pankuch and P. C. Appelbaum, Antimicrob. Agents Chemother., 2004, 48, 4037-4039.

48 J.-M. Lee, S.-H. Kim, H.-Y. Jeong, N.-R. Ahn, H.-G. Roh, J.-W. Cho, B.-C. Chun, S.-T. Oh and J.-S. Park, Fibers Polym., 2014, 15, 1349-1356.

49 A. Guo, W. Zhang and Z. S. Petrovic, J. Mater. Sci., 2006, 41, 4914-4920.

50 C. Defonseka, Practical Guide to Flexible Polyurethane Foams, Smithers Rapra Technology, 2013.

51 S. S. Sheiko, G. Eckert, G. Ignat'eva, A. M. Muzafarov, J. Spickermann, H. J. Räder and M. Möller, Macromol. Rapid Commun., 1996, 17, 283-297.

52 S. S. Sheiko, A. I. Buzin, A. M. Muzafarov, E. A. Rebrov and E. V. Getmanova, Langmuir, 1998, 14, 7468-7474.

53 S. S. Sheiko, A. M. Muzafarov, R. G. Winkler, E. V. Getmanova, G. Eckert and P. Reineker, Langmuir, 1997, 13, 4172-4181.

54 J. Klug, L. A. Pérez, E. A. Coronado and G. I. Lacconi, J. Phys. Chem. C, 2013, 117, 11317-11327. 